PREHOSPITAL CARE

\title{
What are the beliefs and attitudes of paramedics to prehospital thrombolysis? A questionnaire study
}

\author{
J Humphrey, A Walker, T B Hassan
}

Emerg Med J 2005;22:450-451. doi: 10.1136/emj.2004.016998

Background: The Ambulance Services have a critical role in the management of acute myocardial infarction (AMI). Paramedic delivered prehospital thrombolysis (PHT) has been proposed. To the authors' knowledge there has been no research carried out to ascertain the views of paramedics. Methods: The authors conducted a postal questionnaire study of 250 paramedics in the West Yorkshire Metropolitan Ambulance Service (WYMAS). This included the knowledge of risks and benefits of $\mathrm{AMI}$ treatments, and their views on possible paramedic delivered PHT.

Results: 193 paramedics replied (77\%); of these $83 \%$ felt paramedics could deliver PHT, 67\% felt thrombolysis was safe, and only $12 \%$ felt that paramedics should not carry out PHT. There was a similar preference towards autonomous PHT (42\%) and telemetry with physician directed PHT (46\%). $96 \%$ wanted a nationally recognised certificate. There were concerns regarding the risks of AMI treatment, with underestimates of the benefits of aspirin, and overestimates of the benefits of thrombolysis. They also greatly overestimated the risks of thrombolysis in terms of extra deaths (71\%), and bleeding (90\%).

Conclusion: The majority of paramedics in WYMAS responding to the questionnaire supported the principle of PHT. Concerns included the risks of thrombolytic treatment, training, and the medico-legal implications for them as individual paramedics. Models for paramedic thrombolysis for each ambulance service should include the views of paramedics.

$\mathrm{T}$ he Ambulance Services have a critical role in the management of acute myocardial infarction. Originally The NHS Plan $^{1}$ set out the commitment to prehospital thrombolysis. The National Service Framework for Coronary Heart Disease and Reforming Emergency Care $^{2}$ has reinforced the commitment to prehospital thrombolysis (PHT) within the golden hour. The Department of Health has published a review of the CHD National Service Framework thrombolysis targets. ${ }^{3}$ This document has encouraged extending the paramedic role in the management of acute myocardial infarction (AMI) by prehospital 12 lead ECG monitoring and interpretation. In addition, prehospital thrombolysis when call-to-door times for AMI are greater than 30 minutes has been supported. The proposed models of care are autonomous paramedic PHT or telemedicine link with a physician authorising PHT on a named patent basis. To our knowledge there has been no research carried out questioning individual paramedics to ascertain their views of paramedic delivered PHT.

PARTICIPANTS, METHODS, AND RESULTS

West Yorkshire Metropolitan Ambulance Service Trust (WYMAS) provides ambulance services for a predominantly urban population of 2.2 million people. We conducted a questionnaire study of paramedics in WYMAS who had been trained to perform and interpret a 12 lead ECG. Approximately 250 paramedics had been trained at the time of the study and were eligible to participate. We compiled a postal questionnaire, which assessed the knowledge of risks and benefits of AMI treatments. The paramedics had not received any prior evidence based information regarding these drugs. We also included questions asking for their views on the ability of paramedics to carry out PHT and to express an opinion regarding this future role.

A total of 193 paramedics replied to the questionnaire, a response rate of $77 \%$. The results are shown in table 1 .

The majority $(83 \%)$ of paramedics questioned felt paramedics would be capable to deliver PHT, 67\% felt thrombolysis was safe for use by paramedics, and only $12 \%$ felt that paramedics should not carry out PHT at all.

When questioned about the preferred model of paramedic delivered thrombolysis, there was a similar preference towards autonomous PHT (42\%) and telemetry with physician directed PHT (46\%).

A majority (71\%) felt they saw enough patients to carry out PHT, with a high level of confidence, after training, to perform a 12 lead ECG (89\%) and interpret it (83\%).

In addition there was a strong preference for the inclusion of a hospital based training programme $(80 \%)$, and a nationally recognised thrombolysis training certificate for paramedics (96\%).

In the comments section this was reinforced, as many expressed a preference for specialist in-hospital training.

There were concerns regarding the risks of AMI treatment including thrombolysis. This was confirmed by the questionnaire responses in which there were underestimates of the benefits of aspirin treatment, and overestimates of the benefits of thrombolysis. They also greatly overestimated the risks of thrombolysis in terms of extra deaths $(71 \%)$, and bleeding (90\%).

Virtually all (95\%) felt there should be additional pay for the extra responsibility; some felt that thrombolysis training should be optional. There was also apprehension expressed about fear of litigation, personal liability for clinical incidents, and support systems.

\section{COMMENT}

The majority of paramedics in WYMAS responding to this questionnaire support the principle of PHT, although have some specific concerns. These clearly arise from a perception of the risks of thrombolytic treatment, concerns about training and the medico-legal implications for them as

Abbreviations: AMI, acute myocardial infarction; PHT, prehospital thrombolysis; WYMAS, West Yorkshire Metropolitan Ambulance Service. 


\begin{tabular}{|c|c|c|c|}
\hline Beliefs & $\begin{array}{l}\text { Correct } \\
\text { answer }(\%)\end{array}$ & $\begin{array}{l}\text { Overestimate } \\
(\%)\end{array}$ & $\begin{array}{l}\text { Underestimate } \\
(\%)\end{array}$ \\
\hline \multicolumn{4}{|l|}{ Treatment of AMI } \\
\hline What is the overall risk of death in untreated AMI? & 32 & 42 & 26 \\
\hline How many lives are saved giving aspirin in AMI? & 25 & 3 & 72 \\
\hline \multicolumn{4}{|l|}{ How many lives are saved if thrombolysis is given } \\
\hline in the first 1 hour? & 28 & 49 & 23 \\
\hline between $4-12$ hours? & 34 & 42 & 24 \\
\hline \multicolumn{4}{|l|}{ Risks of prehospital thrombolysis } \\
\hline Extra deaths are directly related to thrombolysis & 29 & 71 & 0 \\
\hline Extra strokes are directly related to thrombolysis & 42 & 34 & 24 \\
\hline $\begin{array}{l}\text { Extra major bleeds (ex CVA) are directly related to } \\
\text { thrombolysis }\end{array}$ & 9 & 91 & 0 \\
\hline $\begin{array}{l}\text { What is the future role of paramedics in managing } \\
\text { patients with suspected AMl? }\end{array}$ & (\%) & & \\
\hline $\begin{array}{l}\text { Autonomous diagnosis \& paramedic administration } \\
\text { of PHT }\end{array}$ & 42 & & \\
\hline Telemedicine link to hospital-advice to administer PHT & 46 & & \\
\hline Transport to hospital with no PHT & 12 & & \\
\hline Where should training for thrombolysis take place? & (\%) & & \\
\hline Hospital & 79 & & \\
\hline Prehospital & 2 & & \\
\hline Training school & 19 & & \\
\hline Do you: & Yes (\%) & No (\%) & \\
\hline $\begin{array}{l}\text { Believe PHT will have any significant saving in pain } \\
\text { to needle time? }\end{array}$ & 66 & 34 & \\
\hline Believe PHT is safe for use by paramedics? & 64 & 36 & \\
\hline $\begin{array}{l}\text { Think you will see enough patients with AMI to feel } \\
\text { confident to give PHT? }\end{array}$ & 71 & 29 & \\
\hline Feel this skill should attract a pay increase? & 95 & 5 & \\
\hline \multirow[t]{2}{*}{$\begin{array}{l}\text { Think training should be recognised by a National } \\
\text { CPD Certificate? }\end{array}$} & 96 & 4 & \\
\hline & $\begin{array}{l}\text { Agree/strongly } \\
\text { agree (\%) }\end{array}$ & Neutral (\%) & $\begin{array}{l}\text { Disagree/strongly } \\
\text { disagree (\%) }\end{array}$ \\
\hline I think paramedics are capable of performing PHT & 83 & 11 & 6 \\
\hline $\begin{array}{l}\text { I would feel confident to record a } 12 \text { lead ECG in the } \\
\text { prehospital setting }\end{array}$ & 89 & 7 & 4 \\
\hline $\begin{array}{l}\text { l would feel confident in my interpretation of a } 12 \\
\text { lead ECG }\end{array}$ & 83 & 6 & 11 \\
\hline $\begin{array}{l}\text { On average how frequently do you see patients with } \\
\text { suspected cardiac chest pain? }\end{array}$ & $(\%)$ & & \\
\hline Fewer than 1 per shift & 36 & & \\
\hline 1 per shift & 32 & & \\
\hline 2 per shift & 23 & & \\
\hline 3 per shift & 7 & & \\
\hline More than 3 per shift & 2 & & \\
\hline $\begin{array}{l}\text { How often do you think you would need to give } \\
\text { thrombolysis in order to retain skills? }\end{array}$ & $(\%)$ & & \\
\hline 1 per shift & 3 & & \\
\hline 1 per week & 19 & & \\
\hline 1 per month & 63 & & \\
\hline 1 per year & 13 & & \\
\hline Less than once per year & 2 & & \\
\hline
\end{tabular}

individual paramedics. We have identified potential educational needs; the training for this role should therefore include evidenced based medicine education, in-hospital training, and reassurance regarding medico-legal issues. Models for paramedic thrombolysis for each ambulance service should include the views of paramedics.

\section{Authors' affiliations}

J Humphrey, Barnsley District General Hospital, Barnsley, UK A Walker, Accident \& Emergency Department, Pontefract General Infirmary, Pontefract, UK

T B Hassan, The General Infirmary at Leeds, Leeds, UK
Correspondence to: Dr Alison Walker, Accident \& Emergency Department, Pontefract General Infirmary, Friarwood Lane, Pontefract, UK; alison.walker1@virgin.net

Accepted for publication 30 July 2004

\section{REFERENCES}

1 Secretary of State for Health. The NHS plan. A plan for investment. A plan for reform. London: Stationery Office, 2000.

2 Department of Health. National service framework for coronary heart disease. London: Stationery Office, 2000.

3 Department of Health. Review of early thrombolysis. Faster and better treatment for heart attack patients 2003. Available at http://www.dh.gov.uk/ Home/ $/ \mathrm{fs}_{\text {s }}$ en (accessed 13 April 2005). 